\title{
Urea cycle disorders in Spain: an observational, cross-sectional and multicentric study of 104 cases
}

\author{
Elena Martín-Hernández ${ }^{1 *}$, Luis Aldámiz-Echevarría ${ }^{2}$, Esperanza Castejón-Ponce ${ }^{3}$, Consuelo Pedrón-Giner ${ }^{4}$, \\ María Luz Couce ${ }^{5}$, Juliana Serrano-Nieto ${ }^{6}$, Guillem Pintos-Morell ${ }^{7}$, Amaya Bélanger-Quintana ${ }^{8}$, \\ Mercedes Martínez-Pardo ${ }^{8}$, María Teresa García-Silva', Pilar Quijada-Fraile', Isidro Vitoria-Miñana ${ }^{9}$, Jaime Dalmau' \\ Rosa A Lama-More ${ }^{10}$, María Amor Bueno-Delgado ${ }^{11}$, Mirella del Toro-Riera ${ }^{12}$, Inmaculada García-Jiménez ${ }^{13}$, \\ Concepción Sierra-Córcoles ${ }^{14}$, Mónica Ruiz-Pons ${ }^{15}$, Luis J Peña-Quintana ${ }^{16}$, Inmaculada Vives-Piñera ${ }^{17}$, \\ Ana Moráis ${ }^{10}$, Elena Balmaseda-Serrano ${ }^{18}$, Silvia Meavilla ${ }^{3}$, Pablo Sanjurjo-Crespo ${ }^{2}$ and Celia Pérez-Cerdá ${ }^{19}$
}

\begin{abstract}
Background: Advances in the diagnosis and treatment of urea cycle disorders (UCDs) have led to a higher survival rate. The purpose of this study is to describe the characteristics of patients with urea cycle disorders in Spain.

Methods: Observational, cross-sectional and multicenter study. Clinical, biochemical and genetic data were collected from patients with UCDs, treated in the metabolic diseases centers in Spain between February 2012 and February 2013, covering the entire Spanish population. Heterozygous mothers of patients with OTC deficiency were only included if they were on treatment due to being symptomatic or having biochemistry abnormalities.

Results: 104 patients from 98 families were included. Ornithine transcarbamylase deficiency was the most frequent condition (64.4\%) (61.2\% female) followed by type 1 citrullinemia (21.1\%) and argininosuccinic aciduria (9.6\%). Only 13 patients (12.5\%) were diagnosed in a pre-symptomatic state. $63 \%$ of the cases presented with type intoxication encephalopathy. The median ammonia level at onset was $298 \mu \mathrm{mol} / \mathrm{L}$ (169-615). The genotype of 75 patients is known, with 18 new mutations having been described. During the data collection period four patients died, three of them in the early days of life. The median current age is 9.96 years (5.29-18), with 25 patients over 18 years of age. Anthropometric data, expressed as median and z-score for the Spanish population is shown. $52.5 \%$ of the cases present neurological sequelae, which have been linked to the type of disease, neonatal onset, hepatic failure at diagnosis and ammonia values at diagnosis. 93 patients are following a protein restrictive diet, $0.84 \mathrm{~g} / \mathrm{kg} /$ day (0.67-1.10), 50 are receiving essential amino acid supplements, $0.25 \mathrm{~g} / \mathrm{kg} /$ day (0.20-0.45), 58 arginine, $156 \mathrm{mg} / \mathrm{kg} /$ day (109-305) and 45 citrulline, $150 \mathrm{mg} / \mathrm{kg} /$ day (105-199). 65 patients are being treated with drugs: 4 with sodium benzoate, 50 with sodium phenylbutyrate, 10 with both drugs and 1 with carglumic acid.
\end{abstract}

Conclusions: Studies like this make it possible to analyze the frequency, natural history and clinical practices in the area of rare diseases, with the purpose of knowing the needs of the patients and thus planning their care.

Keywords: Urea cycle disorders, UCDs, N-acetylglutamate synthase, Carbamoylphosphate synthetase 1, Ornithine transcarbamylase, Argininosuccinate synthetase, Citrullinemia type 1, Argininosuccinate lyase, Argininosuccinic aciduria, Arginase 1

\footnotetext{
* Correspondence: emartinhernandez@salud.madrid.org

'Pediatric Rares Diseases Unit, Metabolic and Mitochondrial Diseases,

Pediatric Department, Hospital Universitario 12 de Octubre. Research Institute

( $\mathrm{i}+12)$, Madrid, Spain, Avda de Córdoba s/n, 28041 Madrid, Spain

Full list of author information is available at the end of the article
}

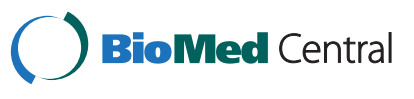

C 2014 Martín-Hernández et al.; licensee BioMed Central Ltd. This is an Open Access article distributed under the terms of the Creative Commons Attribution License (http://creativecommons.org/licenses/by/4.0), which permits unrestricted use, distribution, and reproduction in any medium, provided the original work is properly credited. The Creative Commons Public Domain Dedication waiver (http://creativecommons.org/publicdomain/zero/1.0/) applies to the data made available in this article, unless otherwise stated. 


\section{Background}

The urea cycle is the final common pathway for the excretion of waste nitrogen as well as arginine synthesis [1,2]. Urea cycle disorders (UCDs) are caused by a deficiency of one of the six enzymes in this cycle. Three of the enzymes are mitochondrial, N-acetylglutamate synthase (NAGS), carbamoylphosphate synthetase 1 (CPS1), and ornithine transcarbamylase (OTC), and the other three are cytoplasmic, argininosuccinate synthetase (ASS), argininosuccinate lyase (ASL) and arginase 1 (ARG1). As the metabolic steps take place in two different cellular compartments, two transporters are also necessary: the ornithine/citrulline antiporter ORNT1, deficiency of which causes hyperornithinemia-hyperammonemia-homocitrullinuria syndrome and the glutamate/aspartate antiporter CITRIN, deficiency of which gives rise to type 2 citrullinemia. All these deficiencies are inherited in an autosomal recessive manner, except for OTC deficiency which is inherited in an X-linked recessive manner.

The incidence of UCDs varies between 1:22.1791:53.717 newborns [3-7] although it could be higher, considering that not all the cases are detected by expanded newborn screening (NBS) and many can be undiagnosed cases with a fatal outcome.

The clinical presentation is variable; the onset of severe forms usually occurs during the neonatal period and it is characterized by food refusal, vomiting, lethargy, polypnea, and rapid progression to coma and multiorgan failure [8]. There is high mortality among this type of patients and those who survive experience frequent subsequent decompensation and bad neurological prognosis [9]. The onset of mild forms can occur at any age with hyperammonemic episodes triggered during metabolic stress (infections, vomiting, surgery, etc.) or with more insidious symptoms such as failure to thrive, liver disease, developmental delay, behavioral disorders or psychiatric symptoms [10]. The biochemical data that helps making the diagnosis is hyperammonemia together with the amino acid and organic acid pattern. The diagnosis is confirmed through an enzymatic and/or genetic study. Treatment is primarily based on a low protein diet, essential amino acids (EAA) supplements, arginine and/or citrulline, and the use of nitrogen scavenging drugs such as sodium benzoate (BZ) or sodium phenylbutyrate (PBA) [11]. No protein restriction is necessary when treating NAGS deficiency with carglumic acid.

Diagnostic and treatment advances over recent years, including newborn screening (NBS) for some of the conditions $[12,13]$, acute hyperammonemia treatment guidelines $[11,14,15]$, extracorporeal detoxification [16,17], nutritional therapy [18], nitrogen scavenging drugs [19], liver transplantation $[20,21]$, etc., have decreased the mortality rates, and many patients reach adulthood. However, neurological sequelae are still prominent. Since these are rare conditions and the number of patients in each center is low, it is necessary to conduct multicenter studies to understand the new natural history of the disease. A registry of patients has been started recently in the USA [22] and another one in Europe [23]. In Spain there was no information on patients with these diseases, so the Spanish Association of Inborn Errors of Metabolism (AECOM) has promoted this observational, cross-sectional and multicenter study that aims to find out the number of patients with urea cycle disorders, as well as their clinical and laboratory characteristics, in order to plan their care.

\section{Methods}

Data used in the analysis were collected at enrolment in a national registry of patients with UCDs. The study was carried out by the Spanish urea cycle disorders study group, members of the AECOM. All inherited metabolic diseases (IMD) centers in Spain, covering the entire population of the country, answered a questionnaire regarding clinical and analytical information at diagnosis and at last visit of patients with UCDs alive during the study period.

The inclusion criteria were:

1. Data collection between February 2012 and February 2013, 12 months.

2. Live patients at any time during the study period, even if the patient died later on.

3. Urea cycle disorder diagnosis due to a deficiency of any of the six enzymes of the cycle.

4. Heterozygous mothers of patients with OTC deficiency were only included if they were on treatment due to being symptomatic or having biochemistry anomalies.

Informed consent was obtained for their inclusion in the registry and for anonymous publication of the data. The data were anonymized before their assessment and statistical analysis. The registry was approved by the Ethics Committee of the 12 de Octubre Hospital (Madrid, Spain).

The data obtained at diagnosis was: type of disorder, gender, age at onset of symptoms and age at diagnosis, ethnic origin, UCD family history or family consanguinity, presentation (neonatal, late or pre-symptomatic), diagnostic method (biochemical, enzymatic, genetic), clinical symptoms, biochemical parameters and molecular study. Biochemical and molecular studies were performed over a long period of time in different laboratories using diverse methods, some of them previously published [24-28]. In none of the cases the molecular study was done by nextgeneration sequencing (NGS).

Data obtained on the last visit during the study period was: age, anthropometric data (weight, height and head circumference), liver damage (hypertransaminasemia, 
liver hyper-echogenicity), neurological impairment (developmental delay, mental retardation, learning disorder, behavior disorders, motor disorders and epilepsy), biochemical parameters, dietary treatment (total protein, energy, essential amino acids, L-arginine, L-citrulline) and pharmacological treatment. Anthropometric parameters were collected by standard procedures in each center and expressed as z-scores, using published Spanish population values as a reference [29].

Statistical methods: data are expressed as mean and standard deviation (SD) or median and interquartile range (IQR) for quantitative variables and percentages for qualitative variables. The level of statistical significance was obtained using Chi-square or Fisher's Exact Test for qualitative variables and Student's T-test or the Mann-Whitney $U$ test for quantitative variables.

\section{Results}

\section{Data at diagnosis}

\section{Demographic data}

A total of 104 patients from 98 different families were included, with the following diagnosis: 67 OTC deficiency (64.4\%), 22 ASS deficiency (type 1 citrullinemia) (21.1\%), 10 ASL deficiency (argininosuccinic aciduria) (9.6\%), 2 CPS1 deficiency (1.92\%), 2 ARG1 deficiency (1.92\%) and 1 NAGS deficiency (0.96\%). Some of the patients have been previously published [24-28,30].

Almost half of the patients $(47 \%, 49$ cases) were male and 53\% (55) female. From the 67 cases with OTC deficiency, $38.8 \%$ (26) were male and $61.2 \%$ (41) female (Table 1). Other relatives were affected in $20.4 \%$ of the cases and there was family consanguinity in $5.9 \%$ of the cases. Most patients were European (90.4\%, 94 subjects), with a small number of patients from other geographical origins: 5.7\% (6) from Morocco, and 3.8\% (4) from Latin America.

During the study time 11 new cases were diagnosed, 6 of them were born in that period (3 with neonatal onset and 3 diagnosed by NBS) and 5 had been born in previous years.

The median age at onset, in patients with clinical symptoms, was 12.7 months $(0.2-28)$ and the median age at diagnosis was 16.3 months (0.2-43.2). The median age of asymptomatic patients at diagnosis was 0.46 months (0.17-53).

During the first year $44.2 \%$ of the cases (46) were diagnosed, between 1 year and 6 years, 39.4\% (41), between 6 and 12 years $11.5 \%$ (12), between 12 and 18 years $1.9 \%$ (2) and the remaining $2.8 \%$ (3) were diagnosed in adulthood.

\section{Symptoms and biochemical data at diagnosis}

Symptoms began during the neonatal period in $25.9 \%$ of the cases (27), $61.5 \%$ (64) had a late onset and only $12.5 \%$ (13) were asymptomatic at diagnosis. Therefore, $87.5 \%$ of the patients (91) were index-patients diagnosed due to symptoms. Neurological deterioration "intoxication type" was present in $63 \%$ of the cases. The rest of the symptomatic patients presented other neurological and/or digestive symptoms at onset. Psychiatric symptoms, such as psychosis in the 12 year old NAGSD patient [30],were observed in $1.9 \%$ of the patients.

Of the 13 cases diagnosed in the pre-symptomatic state, 5 were detected through NBS (3 ASSD, 1 ASLD and 1 ARG1D), one was a prenatal diagnosis (ASL deficiency), and the remaining 7 were diagnosed through family history (6 OTCD and 1 ASSD).

Figure 1 shows the type of presentation according to the disorder. $63.6 \%$ of the patients with type 1 citrullinemia had neonatal onset, while in OTC and ASL deficiencies a late onset was more frequent $(77.6 \%$ and $60 \%$, respectively). Among patients with OTC deficiency, 9 had neonatal onset ( 7 males), 52 had late onset (15 males) and 6 were asymptomatic at diagnosis ( 4 males). 4 of the asymptomatic patients were children ( 3 males, 1 female); another one was a heterozygous mother treated

Table 1 Description of the series

\begin{tabular}{|c|c|c|c|c|c|c|}
\hline \multirow[t]{3}{*}{ Disease } & \multirow[t]{3}{*}{ Number (\%) } & \multicolumn{2}{|l|}{ Gender* } & \multicolumn{3}{|l|}{ Presentation* } \\
\hline & & \multirow[t]{2}{*}{ Male } & \multirow[t]{2}{*}{ Female } & \multicolumn{2}{|l|}{ Symptomatic } & \multirow[t]{2}{*}{ Asymptomatic } \\
\hline & & & & Neonatal & Late & \\
\hline OTCD & $67(64.4)$ & $26(38.8)$ & $41(61.2)$ & 9 (13.4) 7 males & $52(77.6) 15$ males & 6 (9) 4 males \\
\hline ASSD & $22(21.1)$ & $13(59)$ & $9(61)$ & $14(63.6)$ & $4(18.2)$ & $4(18.2)$ \\
\hline ASLD & $10(9.61)$ & $6(60)$ & $4(40)$ & $2(20)$ & $6(60)$ & $2(20)$ \\
\hline CPS1D & $2(1.92)$ & $1(50)$ & $1(50)$ & $1(50)$ & $1(50)$ & \\
\hline ARG1D & $2(1.92)$ & $2(100)$ & 0 & $1(50)$ & & $1(50)$ \\
\hline NAGSD & $1(0.96)$ & $1(100)$ & 0 & - & $1(100)$ & - \\
\hline Total & 104 (100) (98 families) & $49(47.1)$ & $55(52.9)$ & $27(26)$ & $64(61.5)$ & $13(12.5)$ \\
\hline
\end{tabular}

OTCD: ornithine transcarbamylase deficiency. ASSD: argininosuccinate synthetase deficiency; ASLD: argininosuccinate lyase deficiency; CPS1D: carbamoylphosphate synthetase 1 deficiency; ARG1D: arginase 1 deficiency; NAGSD: N-acetylglutamate synthase deficiency.

*Number of cases (\%). 


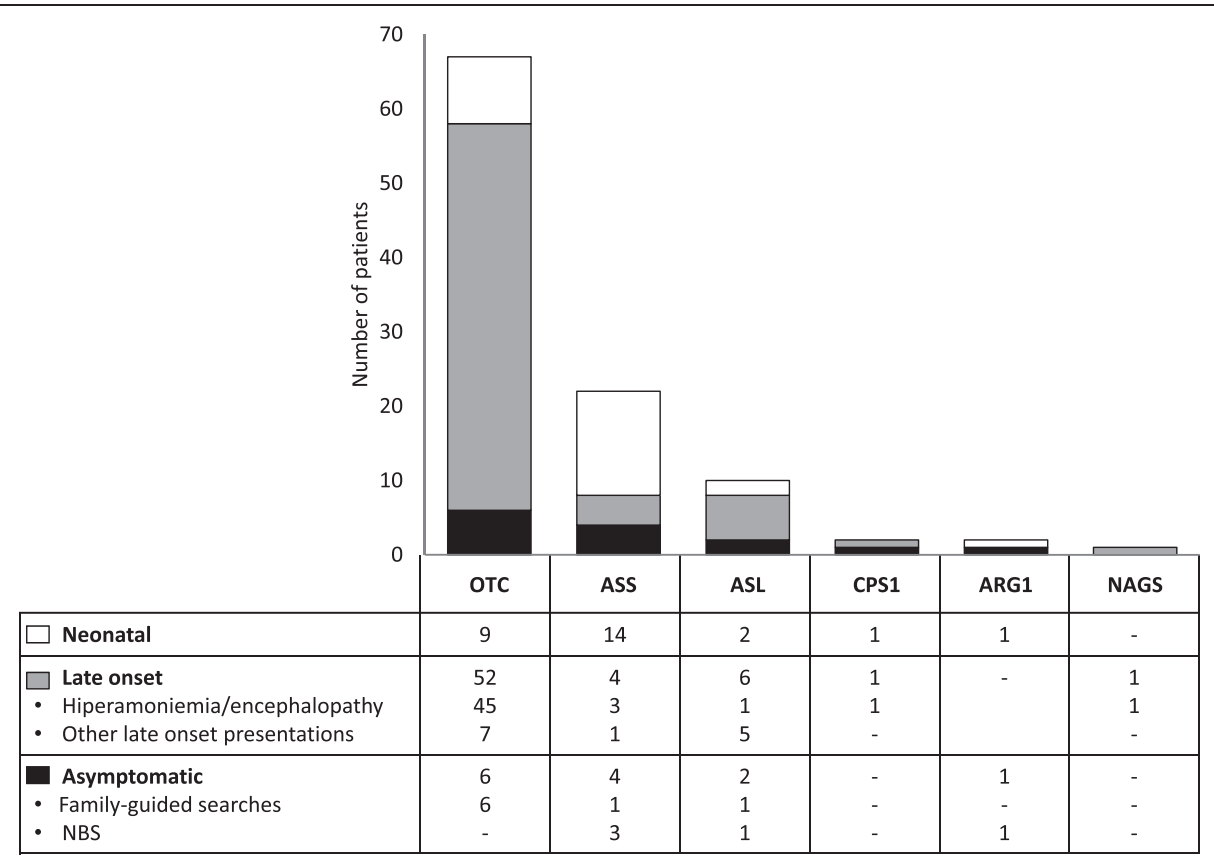

Figure 1 The table under the figure shows the number of cases with neonatal, late or asymptomatic presentation in each disease.

Most of the ASS deficient patients had neonatal onset. Among asymptomatic patients with OTC deficiency only one was a heterozygous mother included and treated because of biochemical abnormalities.

because she had very low levels of citrulline and arginine at diagnosis and the last one was an adult man with biochemical abnormalities, who was also treated in order to prevent an acute hyperammonemic encephalopathy.

With respect to ARG1 deficiency, a very rare disease, there are two patients in our series. The first one is a male diagnosed through NBS with arginine levels of $112 \mu \mathrm{mol} /$ $\mathrm{L}$ at $48 \mathrm{~h}$ of age (reference range: 0.2- 49.54). Ammonia and glutamine were normal (50 and $350 \mu \mathrm{mol} / \mathrm{L}$ respectively) and the diagnosis was confirmed by enzymatic activity in red cells. The second one is a male who presented at 2 days of age with respiratory distress, food refusal and seizures. Ammonia level was $164 \mu \mathrm{mol} / \mathrm{L}$, glutamine $1105 \mu \mathrm{mol} / \mathrm{L}$ and arginine $590 \mu \mathrm{mol} / \mathrm{L}$. He was diagnosed by enzymatic study in red cells.

Median ammonia level at onset in symptomatic patients was $298 \mu \mathrm{mol} / \mathrm{L}$ (169-615) and median glutamine level was $1124 \mu \mathrm{mol} / \mathrm{L}$ (859-1546). Three cases with argininosuccinic aciduria and 1 case with OTC deficiency showed normal values of ammonia and glutamine at onset. 17 patients had biochemical parameters consistent with acute liver failure. Other biochemical data are shown in Table 2. Blood levels of citrulline and arginine in each type of disease are shown in Table 3.

The diagnosis was confirmed through enzymatic activity in $40.4 \%$ (42) and/or through molecular study in $79.8 \%$ (83) of the cases, although we only have available the genotype of $72.1 \%$ (75) of the subjects. In 12 (11 symptomatic, 1 asymptomatic) OTC female patients, despite their mosaic nature, deficient OTC activity was supported in jejunal biopsy.

\section{Molecular genetic data}

The genetic study was available in 79 patients (56 OTC, 14 ASS, 7 ASL, 1 CPS and 1 NAGS). The genotype of $72.1 \%$ of the patients (75) is known. Eight OTC, 2 ASS, 5 ASL, 1CPS and 2 NAGS mutations have not been previously reported.

Table 4 lists the 39 different mutations of the 52 patients (48 families) with OTC deficiency. In 4 OTC deficient patients mutations were not found. Therefore the

Table 2 Biochemical data at diagnosis (excluding asymptomatic patients) and at last visit (all patients)

\begin{tabular}{llll}
\hline Biochemical data * & $\begin{array}{l}\text { At clinical onset } \\
(\mathbf{N}=\mathbf{9 1})\end{array}$ & $\begin{array}{l}\text { At last visit } \\
(\mathbf{N}=\mathbf{9 6})\end{array}$ & $\begin{array}{l}\text { Normal } \\
\text { values }\end{array}$ \\
\hline Ammonia $(\mu \mathrm{mol} / \mathrm{L})$ & $298(169-615)$ & $33(27-42)$ & $10-55\left(80^{* *}\right)$ \\
Glutamine $(\mu \mathrm{mol} / \mathrm{L})$ & $1124(859-1546)$ & $716(545-908)$ & $350-650$ \\
$\begin{array}{l}\text { Prothrombin } \\
\text { activity (\%) }\end{array}$ & $60(32.6-82)$ & $91(85-100)$ & $75-130$ \\
ALT (IU/L) & $76(38-159)$ & $24(16-34)$ & $5-39$ \\
AST (IU/L) & $53.5(36.7-161)$ & $27.5(19-37.2)$ & $5-37$ \\
Bilirrubin (mg/dL) & $0.60(0.43-3.77)$ & $0.53(0.30-0.80)$ & $0.20-1.10$ \\
Albumin (g/L) & $3.79(3-4.41)$ & $4.30(3.90-4.50)$ & $3.80-5.40$ \\
pH & $7.43(7.36-7.46)$ & - & $7.35-7.45$ \\
Bicarbonate (mmol/L) & $21(19-24)$ & - & $23-27$ \\
\hline
\end{tabular}

*Median and interquartile range (IQR); ${ }^{* *}$ Normal values in newborns. 
Table 3 Levels of specific urea cycle amino acids at diagnosis for the different diseases

\begin{tabular}{lll}
\hline Type of UCD & \multicolumn{2}{l}{ Amino acid* } \\
\cline { 2 - 3 } & $\begin{array}{l}\text { Citrulline }(\boldsymbol{\mu} \mathbf{m o l} / \mathbf{L}) \\
(\mathbf{N V}: \mathbf{2 6} \pm \mathbf{8})\end{array}$ & $\begin{array}{l}\text { Arginine }(\boldsymbol{\mu m o l} \mathbf{L}) \\
\mathbf{( N V : ~ 6 4 ~} \pm \mathbf{2 4})\end{array}$ \\
\hline NAGSD, CPS1D, OTCD & $10(7-16)$ & $39(20-59)$ \\
ASSD & $1654(984-2400)$ & $31(17-41)$ \\
ASLD & $173(103-256)$ & $36(24-81)$ \\
ARG1D & $21(20.5-21.5)$ & $351(231-470)$ \\
\hline
\end{tabular}

*Median and interquartile range (IQR).

NV: normal values.

NAGSD: N-acetylglutamate synthase deficiency; CPS1D: Carbamoylphosphate synthetase 1 deficiency; OTCD: Ornithine transcarbamylase deficiency; ASSD: Argininosuccinate synthetase deficiency; ASLD: Argininosuccinate lyase deficiency; ARG1D: Arginase 1deficiency.

sensitivity of our genetic studies in OTC was $92.85 \%$. Table 4 includes information on the gender, time and severity at onset and neurological situation at last visit. References of previously reported cases are indicated next to the number of the patient [24-27]. The most frequent mutation was p.Arg129His which was identified in 5 patients ( 3 females) from 4 families, all of them with good neurologic outcome. On the other hand, the two patients with a deletion of the whole OTC gene are very symptomatic. For other frequent mutations, such as $\mathrm{p}$. Arg40His or p.Gly195Arg, neurological outcome is related more to the time and severity at onset rather than the mutation itself, with poorer outcome of index-cases than asymptomatic siblings diagnosed through family history (Table 4).

We include eight new mutations, not previously reported in the public database $\mathrm{HGMD}^{\circ}$ [31]: p.Thr343Arg, p.Glu273del, p.Thr93Ileu, p.Lys88Thr, c.298 + 1G >C (IVS3 + 1G > C), p.Ileu85Ser, p.Phe48Leufs*16, andp. Lys210Asnfs*20. The first six mutations were identified in 2 males and 4 females with late onset and without neurological damage at their last visit. The mutation $\mathrm{p}$. Lys210Asnfs*20 was found in a girl that suffered acute encephalopathy at 6 months of age and has developmental delay in the outcome. Finally, the p.Phe48Leufs*16 mutation was identified in a case with onset two days after birth with ammonia levels of $4584 \mu \mathrm{mol} /$ $\mathrm{L}$ who only survived a few hours.

Table 5 includes the information of the patients with ASS, ASL, CPS and NAGS deficiency. We have no molecular genetic data for any of the cases with argininemia.

Regarding type 1 citrullinemia, twelve different mutations in the ASS1 gene were identified in 14 subjects. The most frequent mutation, p.Gly390Arg, was identified in homozygosis in two patients with neonatal onset and poor outcome. The 3 patients with mutation p. Arg86Cys in homozygosis, diagnosed through NBS, late onset hepatic failure or neurological symptoms, had no neurological sequelae in their last visit. Two new mutations of the ASS1 gene have been identified: p. Met186Arg was identified in homozygosis in one patient of Romanian origin who presented acute encephalopathy "intoxication type" and multiorgan failure in the neonatal period. The other new mutation, p.Thr91Ala, was identified as heterozygous in a case diagnosed by NBS and who remains asymptomatic to date.

Nine mutations in the ASL gene were identified in seven patients (six families) with argininosuccinic aciduria, five of which have not been previously described: $\mathrm{p}$. Tyr45Asn, p.Gly316Glu, p.Pro208Arg, p.Gly301Arg and p.Arg456Gln. All these mutations were found in patients with late onset neurological symptoms, many times without hyperammonemia, except for the p.Arg456Gln mutation which was identified in a patient diagnosed by NBS who remains asymptomatic at 4 years of age.

\section{Current situation, data at last visit Demographic data}

During the 12-month data collection period four patients died, three in the neonatal period (2 OTCD males and 1 ASSD) and one at the age of 9 (CPS1D). Thus, in February of 2013 there were 100 patients registered with UCDs in Spain.

The median age at last visit was 9.96 years (5.29-18). $25 \%$ of the patients were over 18 years, $16 \%$ were between 12 and 18 years, 33\% were between 6-12 years, $22 \%$ were between 1-6 year and only $4 \%$ of them were under the age of one year.

\section{Anthropometric data}

Table 6 shows the weight, height, and head circumference for the different age groups at last visit and the BMI for the adult group. The Z-score, calculated according to the tables by Hernández et al. [29] for the Spanish population, are also indicated. The z-score of weight was below -2SD in 4.3\% (4/92) of the patients, the z-score of height was below -2SD in 13\% (12/89) of the patients and the z-score of head circumference was below -2SD in $20 \%(5 / 20)$ of the patients.

\section{Biochemical data}

Table 2 shows some biochemical data at last visit, which are within normal values, except for a slight increase in glutamine.

\section{Outcome}

Neurological sequelae were seen in $52.5 \%$ (53) of the patients. Learning disorders in 50, developmental delay in 33 , behavior disorders in 24 , epilepsy in 15 , motor disorders in 14, and psychiatric disorders in 6 . Brain magnetic resonance imaging was performed in 46 patients, 22 of which were normal. Neuropsychological assessment was carried out in 26 patients (13 WISC-IV, 5 McCarthy, 4 
Table 4 Mutations identified in $\mathbf{5 2}$ patients (48 families) with OTC deficiency

\begin{tabular}{|c|c|c|c|c|c|}
\hline Patient $\mathrm{n}^{\circ} /$ gender/[reference] & Nucleotide & Protein & Onset & Neurologic damage & Alive \\
\hline $4 M$ & c. $1028 \mathrm{C}>\mathrm{G}^{*}$ & p.Thr343Arg* & Late & No & Yes \\
\hline $5 \mathrm{~F}$ & $\mathrm{c} .663+2 \mathrm{~T}>\mathrm{C}(\mathrm{IV} 6+2 \mathrm{~T}>\mathrm{C})$ & & Late & Yes & Yes \\
\hline $7 \mathrm{~F}$ & c. $533 \mathrm{C}>\mathrm{T}$ & p.Thr178Met & Late & No & Yes \\
\hline $8 M$ & $c .421 C>T$ & p.Arg141Term & Late & No & Yes \\
\hline $10 \mathrm{~F}$ & c. $533 \mathrm{C}>\mathrm{T}$ & p.Thr178Met & Late & Yes & Yes \\
\hline $11 \mathrm{~F}$ & c. $914 C>G$ & p.Pro305Arg & Late & No & Yes \\
\hline $12 \mathrm{M}$ & c. $604 \mathrm{C}>\mathrm{T}$ & p.His202Tyr & Late & No & Yes \\
\hline $13 \mathrm{~F}[27]$ & c. $287 C>\mathrm{T}$ & p.Ser96Phe & Late & No & Yes \\
\hline $14 \mathrm{~F}$ & del814-816GAG* & p.Glu273del* & Late & No & Yes \\
\hline $16 \mathrm{~F}$ & $\mathrm{c} .386+1 \mathrm{G}>\mathrm{A}(\mathrm{IVS} 4+1 \mathrm{G}>\mathrm{A})$ & & Late & Yes & Yes \\
\hline $20 \mathrm{M}$ & c. $365 A>G$ & p.Gln122Gly & Late & Yes & Yes \\
\hline $21 \mathrm{M}$ & c. $119 \mathrm{G}>\mathrm{A}$ & p.Arg $40 \mathrm{His}$ & $\mathrm{A}, \mathrm{FH}$ & No & Yes \\
\hline $22 \mathrm{M}$ & c. $264 \mathrm{~A}>\mathrm{T}$ & p.Lys88Asn & Late & No & Yes \\
\hline $25 \mathrm{M}$ & c. $119 \mathrm{G}>\mathrm{A}$ & p.Arg $40 \mathrm{His}$ & Late & No & Yes \\
\hline $27 \mathrm{~F}$ & C. $67 \mathrm{C}>\mathrm{T}$ & p.Arg23Term & Late & Yes & Yes \\
\hline $32 \mathrm{~F}[24]$ & c. $386 G>A$ & p.Arg129His & Late & No & Yes \\
\hline $33 \mathrm{~F}[25]$ & c. $205 C>T$ & p.GIn69Term & Late & Yes & Yes \\
\hline $36 \mathrm{~F}[25]$ & delOTC gene $>1.6 \mathrm{Mb}$ & & Late & Yes & Yes \\
\hline $37 \mathrm{~F}$ & c. $583 \mathrm{G}>\mathrm{A}$ & p.Gly195Arg & $\mathrm{A}, \mathrm{FH}$ & No & Yes \\
\hline $38 \mathrm{~F}$ & c. $386 G>A$ & p.Arg129His & Late & No & Yes \\
\hline $40 \mathrm{M}[27]$ & c. $386+5 G>A($ IVS4 + 5G > A) & & Neonatal & No & Yes \\
\hline $45 \mathrm{~F}$ & c. $278 \mathrm{C}>\mathrm{T}^{*}$ & p.Thr93lleu* & Late & No & Yes \\
\hline $48 \mathrm{M}[24]$ & C. $386 G>A$ & p.Arg129His & Neonatal & No & Yes \\
\hline $49 \mathrm{M}$ & $\mathrm{c} .86 \mathrm{C}>\mathrm{T}$ & p.Ala209Val & Late & Yes & Yes \\
\hline $50 \mathrm{~F}$ & C. $476 \mathrm{~T}>\mathrm{C}$ & p.lle159Thr & Late & Yes & Yes \\
\hline $51 \mathrm{M}[24]$ & c. $386 G>A$ & p.Arg129His & Late & No & Yes \\
\hline $52 \mathrm{~F}[25]$ & c. $514 \mathrm{~A}>\mathrm{T}$ & p.lle172Phe & Late & No & Yes \\
\hline $53 \mathrm{M}$ & c. $829 \mathrm{C}>\mathrm{T}$ & p.Arg277Trp & Late & No & Yes \\
\hline $54 \mathrm{M}[26]$ & c. $571 \mathrm{C}>\mathrm{T}$ & p.Leu191Phe & Late & Yes & Yes \\
\hline $55 \mathrm{M}$ & c. $622 \mathrm{G}>\mathrm{A}$ & p.Ala208Thr & Late & Yes & Yes \\
\hline $56 M$ & c. $263 \mathrm{~A}>\mathrm{C}^{*}$ & p.Lys88Thr* & Late & No & Yes \\
\hline $59 M$ & c. $622 \mathrm{G}>\mathrm{A}$ & p.Ala208Thr & $\mathrm{A}, \mathrm{FH}$ & No & Yes \\
\hline $60 \mathrm{~F}$ & c. $298+1 G>C(\text { IVS3 + 1G > C })^{*}$ & & Late & No & Yes \\
\hline $68 \mathrm{~F}$ & c. $1018 \mathrm{C}>\mathrm{T}$ & p.Ser340Pro & Late & Yes & Yes \\
\hline $69 \mathrm{~F}[26]$ & c. $1022 C>T$ & p.Leu341Pro & Late & Yes & Yes \\
\hline $72 \mathrm{~F}$ & c. $482 A>G$ & p.Asn161Asp & Late & No & Yes \\
\hline $73 \mathrm{M}$ & c.144delT* & p.Phe48Leufs*16* & Neonatal & - & No \\
\hline $74 \mathrm{~F}$ & c. $254 \mathrm{~T}>\mathrm{G}^{*}$ & p.lleu85Ser* & Late & No & Yes \\
\hline $75 \mathrm{~F}$ & $c .583 G>A$ & p.Gly195Arg & $\mathrm{A}, \mathrm{FH}$ & No & Yes \\
\hline $76 \mathrm{M}$ & c. $119 \mathrm{G}>\mathrm{A}$ & p.Arg $40 \mathrm{His}$ & $\mathrm{A}, \mathrm{FH}$ & No & Yes \\
\hline $77 \mathrm{M}$ & C.119G > A & p.Arg40His & Late & Yes & Yes \\
\hline $79 \mathrm{~F}$ & c. $154 \mathrm{G}>\mathrm{A}$ & p.Glu52Lys & Late & Yes & Yes \\
\hline $80 \mathrm{~F}$ & c. $583 G>A$ & p.Gly195Arg & Late & Yes & Yes \\
\hline $82 M$ & c. $622 \mathrm{G}>\mathrm{A}$ & p.Ala208Thr & Late & Yes & Yes \\
\hline
\end{tabular}


Table 4 Mutations identified in 52 patients (48 families) with OTC deficiency (Continued)

\begin{tabular}{|c|c|c|c|c|c|}
\hline $83 \mathrm{M}$ & c.932 T > A & p.Val311Glu & Neonatal & No & Yes \\
\hline $88 \mathrm{~F}$ & c. $605 \mathrm{~A}>\mathrm{T}$ & p.His202Leu & Late & No & Yes \\
\hline $91 \mathrm{~F}$ & c.386 + 2T > C (IVS4 + 2T>C) & & Late & No & Yes \\
\hline $94 \mathrm{~F}$ & c.630delA* & p.Lys 210 Asnfs*20* & Late & Yes & Yes \\
\hline $95 \mathrm{~F}$ & delOTC gene $>1.6 \mathrm{Mb}$ & & Late & Yes & Yes \\
\hline $97 \mathrm{M}$ & c. $958 \mathrm{C}>\mathrm{T}$ & p.Arg320Term & Neonatal & - & No \\
\hline $100 \mathrm{~F}$ & c. $386 G>A$ & p.Arg129His & Late & No & Yes \\
\hline $103 \mathrm{~F}[27]$ & c. $211 \mathrm{G}>\mathrm{T}$ & p.Gly71Term & Late & Yes & Yes \\
\hline
\end{tabular}

In bold: *mutations not published in the public database HGMD [31].

F: female; M: male.

A: asymptomatic; $\mathrm{FH}$ : family history.

Cases 21 and 25, 32 and 51, 37 and 75, 76 and 77 are relatives.

[24-27]: references of primary publications where these patients and their mutations were published.

Table 5 Mutations identified in patients with ASS, ASL, CPS1 and NAGS deficiencies

\begin{tabular}{|c|c|c|c|c|c|}
\hline $\begin{array}{l}\text { Patient } \mathrm{n}^{\circ} / \\
\text { [reference] }\end{array}$ & Gene & Nucleotide & Protein & Onset & $\begin{array}{l}\text { Neurologic } \\
\text { damage }\end{array}$ \\
\hline 1 & ASS & c. $256 C>T / C .256 C>T$ & p.Arg86Cys / p.Arg86Cys & Late & No \\
\hline 3 & ASS & c.206 T > C / c.206 T > C & p.Val69Ala / p.Val69Ala & Neonatal & Yes \\
\hline 18 & ASS & c.557 T > G / c.557 T > G* & p.Met186Arg / p.Met186Arg* & Neonatal & Yes \\
\hline 24 & ASS & c.970G > A / c.970G > A & p.Gly324Ser / p.Gly324Ser & Late & No \\
\hline 41 & ASS & c.971G > T / c.1168G > A & p.Gly324Val / p.Gly390Arg & Neonatal & Yes \\
\hline 46 & ASS & C.1168G > A /c.1168G > A & p.Gly390Arg / p.Gly390Arg & Neonatal & Yes \\
\hline $66[28]$ & ASS & C. $350 G>A / C .1168 G>A$ & p.Gly117Asp / p.Gly390Arg & Late & Yes \\
\hline 84 & ASS & c. $.970 G$ $>$ A / c.271A > G* & p.Gly324Ser / p.Thr91Ala* & A, NBS & No \\
\hline 85 & ASS & c. $256 C>T / c .256 C>T$ & p.Arg86Cys / p.Arg86Cys & A, NBS & No \\
\hline 86 & ASS & c. $256 C>T / c .256 C>T$ & p.Arg86Cys / p.Arg86Cys & Late & No \\
\hline $96^{\mathrm{D}}$ & ASS & c.1168G > A /c.1168G > A & p.Gly390Arg / p.Gly390Arg & Neonatal & - \\
\hline 98 [28] & ASS & c.323G > T + c.356C > T / NF & p.Arg108Leu + p.Thr119lle / NF & Neonatal & Yes \\
\hline 99 & ASS & c.892delG / c.1168G > A & p.Glu298Argfs*/ p.Gly390Arg & Neonatal & Yes \\
\hline 101 & ASS & c.919C > T / NF & p.Arg307Cys / NF & A, NBS & No \\
\hline 9 & ASL & c. $133 \mathrm{~T}>\mathrm{A}^{*} / \mathrm{c} .947 \mathrm{G}>\mathrm{A}^{*}$ & p.Tyr45Asn* / p.Gly316Glu* & Late & Yes \\
\hline 29 & ASL & c. $623 \mathrm{C}>\mathrm{G} / \mathrm{c} .623 \mathrm{C}>\mathrm{G}^{*}$ & p.Pro208Arg / p.Pro208Arg* & Late & Yes \\
\hline 30 & ASL & c. $623 \mathrm{C}>\mathrm{G} / \mathrm{c} .623 \mathrm{C}>\mathrm{G}$ & p.Pro208Arg / p.Pro208Arg & Late & Yes \\
\hline 39 & ASL & c.338G > A / c.338G > A & p.Arg113Gln /p.Arg113Gln & A, Prenatal & Yes \\
\hline 47 & ASL & $c .532 \mathrm{G}>\mathrm{A} / \mathrm{c} .901 \mathrm{G}>\mathrm{A}^{*}$ & p.Val178Met / p.Gly301Arg* & Late & Yes \\
\hline 71 & ASL & $\mathrm{c} .1143+1 \mathrm{G}>\mathrm{T} / \mathrm{c} .1143+1 \mathrm{G}>\mathrm{T}$ & - & Neonatal & Yes \\
\hline 81 & ASL & c. $1135 \mathrm{C}>\mathrm{T} / \mathrm{c} .1367 \mathrm{G}>\mathrm{A}^{*}$ & p.Arg379Cys / p.Arg456Gln* & A, NBS & No \\
\hline 19 & CPS1 & c. $2549 \mathrm{G}>\mathrm{T}^{*} / \mathrm{NF}$ & p.Arg850Leu* / NF & Late & Yes \\
\hline $93[30]$ & NAGS & c. $499 A>G^{*} /$ c. $.916-2 A>G^{*}$ & p.Met167Val */ & Late & No \\
\hline
\end{tabular}

In bold: *Mutations not published in the public database HGMD [31].

A: asymptomatic; NBS: newborn screening; D: Dead in the neonatal period; NF: not found.

Patients 29 and 30 are siblings.

$[28,30]$ : references of primary publications where these patients were published. 
Table 6 Anthropometric data according to age group

\begin{tabular}{|c|c|c|c|c|c|}
\hline$N=96$ & $\begin{array}{l}0-1 \text { year } \\
(N=4)\end{array}$ & $\begin{array}{l}1-6 \text { years } \\
(\mathrm{N}=20)\end{array}$ & $\begin{array}{l}\text { 6-12 years } \\
(\mathrm{N}=33)\end{array}$ & $\begin{array}{l}12-18 \text { years } \\
(N=16)\end{array}$ & $\begin{array}{l}>18 \text { years }^{* *} \\
(\mathrm{~N}=23)\end{array}$ \\
\hline Age (years)* & $0.68(0.21-0.75)$ & $4.10(2.98-4.97)$ & $8.61(7.50-10.2)$ & $15(14.1-17)$ & $25.3(21.2-33.3)$ \\
\hline Weight $(\mathrm{kg})^{*}$ & $8.25(5.03-8.63)$ & $13.7(12.8-16.7)$ & $28(23.9-31.7)$ & $54.1(46.9-66.7)$ & $60(54.2-75)$ \\
\hline Z-score & -0.28 & -0.53 & -0.008 & 0.1 & 0.17 \\
\hline Height $(\mathrm{cm})^{*}$ & $67.5(58.2-70.7)$ & 95 (91-106) & 124(120-133) & $160(150-176)$ & $161(153-171)$ \\
\hline Z-score & 0.71 & -0.48 & -0.14 & -0.06 & -0.63 \\
\hline $\mathrm{HC}(\mathrm{cm})^{*}$ & $43.2(39.2-43.9)$ & $48.5(46.5-49.8)$ & $50(49.5-53)$ & $* * *$ & $* * *$ \\
\hline Z-score & -0.85 & -1.16 & -0.68 & & \\
\hline
\end{tabular}

*Data reflects median and interquartile range. z-score from tables by Hernández et al [29]. **BMI of adult patients is 23.8 (21.6-27.9).

***No data presented since only observations from 2 patients.

HC: Head circumference.

Brunet-Lezine, 1 Bayley, 1 Kaufman, 1 Llevant, and 1 Wechsler); the mean intelligence quotient was $87 \pm 19$. A correlation between the presence of neurological sequelae and the type of disease, type of presentation, liver failure at onset, and ammonia and glutamine levels at diagnosis was seen (Table 7). Neurological outcome was worse in patients with CPS1D and ASLD and in those with neonatal presentation, liver failure at onset and higher levels of ammonia and glutamine at diagnosis.

Only seven patients (7\%) have liver disease, which presents in the form of persistent or intermittent hypertransaminasemia or liver hyper-echogenicity. They are 4 OTCD (3 females) and 3 ASLD patients.

\section{Treatment}

Dietary treatment was prescribed in 93 patients. Tube feeding was only prescribed in nine cases (8.91\%). The patient with NAGS deficiency, the patients that underwent transplantation and two adult cases with OTC deficiency had no dietary restrictions at the time of the study.

Table 7 Clinical and biochemical data in relation to neurological outcome

\begin{tabular}{|c|c|c|c|c|}
\hline & $\mathbf{N}$ & $\begin{array}{l}\text { With neurological } \\
\text { impairment \% (N) }\end{array}$ & $\begin{array}{l}\text { Without neurological } \\
\text { impairment \% (N) }\end{array}$ & $\mathrm{p}$ \\
\hline \multicolumn{5}{|l|}{ Disease } \\
\hline OTC & 65 & 44.6 (29, 7 males) & $55.4(36,17$ males $)$ & $0.043^{*}$ \\
\hline ASS & 21 & $66.7(14)$ & $33.4(7)$ & \\
\hline ASL & 10 & $80(8)$ & $20(2)$ & \\
\hline CPS1 & 2 & $100(2)$ & 0 & \\
\hline ARG1 & 2 & 0 & $2(100)$ & \\
\hline NAGS & 1 & 0 & $1(100)$ & \\
\hline \multicolumn{5}{|l|}{ Presentation } \\
\hline Neonatal & 24 & $75(18)$ & $25(6)$ & $0.002^{*}$ \\
\hline Late & 64 & $51.6(33)$ & $48.4(31)$ & \\
\hline Asymptomatic & 13 & $15.4(2)$ & $84.6(11)$ & \\
\hline \multicolumn{5}{|l|}{ Hepatic failure at diagnosis } \\
\hline Yes & 17 & $82.3(14)$ & $17.7(3)$ & $0.005^{*}$ \\
\hline No & 82 & $45.1(37)$ & $54.9(45)$ & \\
\hline Laboratory test at diagnosis & & Median (IQR) & Median (IQR) & \\
\hline Ammonia $(\mu \mathrm{mol} / \mathrm{L})$ & 92 & $400(200-690)$ & $174(67.2-270)$ & $<0.001^{* *}$ \\
\hline Glutamine ( $\mu \mathrm{mol} / \mathrm{L})$ & 77 & $1126(891-1672)$ & 917 (751-1196) & $0.019^{* *}$ \\
\hline
\end{tabular}

Neurological outcome was correlated with the type of UCD disease, type of presentation, presence of liver failure at onset and ammonia and glutamine level at diagnosis. The level of statistical significance was obtained using Pearson chi-square* for qualitative variables and the Mann-Whitney $U$ test** for quantitative variables. 
In Table 8 the median intake of protein, energy and EAAs in different groups of age is shown and compared to the $\mathrm{WHO} / \mathrm{FAO} / \mathrm{UN}$ recommendations [32] and the UK prescriptions for these patients [33]. Protein and energy intake decreased with age, being slightly below recommendations in the adult group. 50 patients received EAA supplements (20-30\% of total protein intake).

Fifty-eight patients were receiving arginine supplementation (2 CPS1D, 29 OTCD, 18 ASSD, and 9 ASLD) at 156 (109-305) mg/kg/day. Doses were significantly higher in patients with ASSD/ASLD, 165 (120-461) $\mathrm{mg} / \mathrm{kg} / \mathrm{day}$, in comparison to patients with OTCD/CPS1D, 136 (80250) (p 0.022). Forty-five patients (44 OTCD and 1 CPS1D) were receiving citrulline at doses of 150 (105-199) $\mathrm{mg} / \mathrm{kg} /$ day. Twelve of them (11 OTCD and 1 CPS1D) received supplementation of both amino acids, arginine at 115 (55-224) and citrulline at 201 (57-242) mg/kg/day.

$63.4 \%$ of the patients (64) received nitrogen scavenging drugs $(68.2 \%$ of the symptomatic patients and $30.8 \%$ of the asymptomatic patients), most of them sodium phenylbutyrate (PBA) and a much smaller proportion sodium benzoate or combined treatment (Table 9). The mean age of the patients in treatment with PBA was $10.9 \pm 8.3$ years and that of patients treated with BZ was $24.2 \pm 11.6$ years $(\mathrm{p}<0.0045)$. The patient with NAGS deficiency was in treatment with carglumic acid. Other pharmacological treatments received by our UCD patients were: carnitine in 45 patients, vitamin compounds in 25 , calcium and vitamin D in 11, and antiepileptic drugs in 12.

Liver transplantation was performed in 5 patients, 4 with OTCD ( 3 females) and 1 with citrullinemia. Two of these patients with OTCD have learning disorders; the rest have no neurological sequelae. There are no food restrictions in their diet and none of the patients receive treatment with nitrogen scavenging drugs. Two patients with OTCD receive 50 and $100 \mathrm{mg} / \mathrm{kg} /$ day of citrulline, respectively.

\section{Discussion}

We present the data of the first registry of patients with UCDs in Spain. Since these are rare diseases and there
Table 9 Pharmacological treatment

\begin{tabular}{lll}
\hline Drug & Patients $(\mathbf{N})$ & Mean \pm SD $(\mathbf{m g} / \mathbf{k g} /$ day $)$ \\
\hline Sodium phenylbutyrate & 50 & $250 \pm 158$ \\
Sodium benzoate & 4 & $184 \pm 92.3$ \\
Combined treatment & 10 & \\
$\quad$ Sodium phenylbutyrate & & $250 \pm 134$ \\
$\quad$ Sodium benzoate & & $165 \pm 80.5$ \\
Carglumic acid & 1 & 15 \\
\hline
\end{tabular}

are few patients in each center, most publications on UCDs focus on partial aspects of the disease and only a few describe the natural history of the disease and the current situation of the patients. Recently the data of the American registry [22], a European non-classical UCDs series [34], and the data of the patients in Finland between 1998 and 2007 [6] have been published. The comparison between these series of patients is difficult, particularly due to the differences in the percentage of OTC asymptomatic heterozygous mothers and in the percentage of cases diagnosed by newborn screening. Asymptomatic heterozygous females have not been included in our study and $87.5 \%$ of our patients presented symptoms at onset, mostly acute encephalopathy.

Data from 104 cases were collected during one year, 11 of which were diagnosed over this period. As in other UCDs series, the most frequent condition was OTCD (64. 4\%, 61.2\% females) followed by ASSD and ASLD; the remaining conditions were present in a much lower proportion.

Assuming these were all the cases in Spain in that period, and according to the population data from the Spanish Statistical office [35] (46,609,652 inhabitants and 425,533 newborns), the period prevalence would be 1:448,169 inhabitants and the incidence 1:70,922 newborns. The incidence is lower to that found in other epidemiological studies, e.g., 1:22.179 in the West Midlands in the United Kingdom [5], 1: 39.000 in Finland [6], 1: 41.506 in Italy [4], 1:53.717 in Canada [3] and 1:35.000 in USA [7]. This could be due to the fact that the data was collected for only one year and the age at diagnosis

Table 8 Diet treatment according to age group

\begin{tabular}{|c|c|c|c|c|c|}
\hline Age $(\mathrm{N}=93)$ & $0-1 y(N=4)$ & & $1-10 y(N=47)$ & $11-18 y(N=20)$ & $>18 y(N=22)$ \\
\hline Total proteins (g/kg/day) & $1.86(0.90-2.95)$ & & $0.95(0.7-1.2)$ & $0.84(0.65-0.94)$ & $0.7(0.57-0.92)$ \\
\hline Energy (calories) (kcal/kg/day) & $102(92.5-140)$ & & $72(58-95)$ & $40(32-43,5)$ & $36(30-42)$ \\
\hline Essential Aminoacids (g/kg/day) & $0.39(0.2-0.5)$ & & $0.3(0.27-0.43)$ & $0.25(0.14-0.48)$ & $0.2(0.11-0.41)$ \\
\hline Age & $<6 \mathrm{~m}$ & $6-12 \mathrm{~m}$ & $1-10 y$ & $11-16 y$ & $>16 y$ \\
\hline WHO/FAO/UNU* (safe levels proteins) & 1.77 & 1.31 & $0.92-1.14$ & $0.84-0.90$ & $0.84-0.87$ \\
\hline UK practice $(\mathrm{N}=45)^{* *}$ Proteins & $2(0.7-2.5)$ & $1.6(1.2-1.8)$ & $1.3(1-1.7)$ & $0.9(0.7-1.4)$ & $0.8(0.4-1.2)$ \\
\hline
\end{tabular}

Data reflects median and IQR.

$\mathrm{N}=$ number of patients on diet.

y: years; m: months; ${ }^{*}$ Who/FAO/UNU Expert consultation (2007) [32].

**Adam et al. J Hum Nutr Diet 2013; 25: 398-404 [33]. 
of these diseases is in many cases after the age of one, since OTC deficiency, the most frequent of the UCDs, is not detected by NBS. Furthermore, the expanded NBS is still not performed in all the regions in Spain. Considering that in our series more than half of the cases (55.8\%) were diagnosed after 1 year of age, the estimated incidence would be at least double of what we have found.

The median age of our patients at last visit was 9.6 years, $25 \%$ of which were over 18 years and $16 \%$ were between 12 and 18 years. In the Finnish series [6], the mean age was 13 years, and in European non-classical UCD series [34] the mean age was 18 years (50\% of adults). This indicates that there is a need to establish adult centers with specialists for the follow up of this type of patients.

Great heterogeneity was observed regarding the molecular genetic data. A total of 63 different mutations were identified in 98 alleles, $18(18.3 \%)$ of them are newly described in this work (Tables 4 and 5). Six of the eight new mutations in patients with OTC deficiency (p.Thr343Arg, p.Glu273del; p.Thr93Ileu, p.Lys88Thr, p.Ileu85Ser and c.298+1G >C) were identified in patients with late onset and no neurological symptoms at last visit, meaning these mutations could be related to a good prognosis, although the gender of the patients (4 females) could have contributed to this good outcome. Conversely, the new and presumably deleterious mutation, p.Phe48Leufs"16, was identified in a severe case of a male with neonatal onset. The most frequent mutation in OTCD was p.Arg129His identified in 5 patients with good neurological outcome. This mutation was described for the first time in 3 of our patients [24]. The second mutation in frequency was p.Arg40His which has already been described in patients with variable phenotype including patients without symptoms [36-38].

None of our patients with type 1 citrullinemia had mutations previously associated with the mild forms of the condition, p.Trp179Arg, p.Val263Met, or p.Gly362Val [39]. Nevertheless, we identified the mutation p. Arg86Cys and the new p.Thr91Ala in four patients with a good neurological outcome, two of them detected by NBS, suggesting these two changes could be related to good prognosis of the disease.

Regarding argininosuccinic aciduria, from the five new mutations identified, p.Arg456Gln was detected in one patient diagnosed by NBS and without neurological damage at the age of four. The other mutation in this patient was p.Arg379Gly, previously associated with a mild phenotype when homozygous [40]. We cannot know if the good neurological evolution of this patient is due to the mild effect of the mutations on the protein function or to the early diagnosis and treatment.

In general, the great genetic heterogeneity in our short series of ASS and ASL deficient patients defies performing a realistic genotype phenotype correlation.
This is the first study that shows anthropometric data in a large series of patients with UCDs. The z-score of the weight and height was in the normal range for Spanish population in all the age groups, although some patients were bellow -2SD (Table 6). The Z-score for the height in the adult group (-0.6) was the lowest, which could be related to the fact that they are the patients with a longer follow-up, but also because during their first years of life they did not benefit from the treatments and nutritional formulas we have today. In this study we have not collected data such as essential fatty acids, vitamins, trace elements, etc., that would inform us of the nutritional status of patients, but we must point out that the levels of albumin are within normal values (Table 2).

As already stated, it is difficult to compare between the series regarding the presence of neurological damage because the inclusion criteria differ and because the establishment of the expanded NBS in certain countries has changed the natural history of the disease for some of these disorders (ASSD, ASLD, and ARG1D), improving their prognosis $[41,42]$. In our series, that does not include asymptomatic heterozygous mothers and only $12.5 \%$ of the cases were diagnosed in a pre-symptomatic state, $52.5 \%$ of the cases had neurological complications. In the American series, in which $48 \%$ of the OTC patients were asymptomatic heterozygous females, $39 \%$ of the patients had psychomotor or intellectual retardation and 35\% learning disorders [22]. In the European nonclassical UCDs series with $49 \%$ asymptomatic cases at diagnosis, 36\% had mental retardation or developmental delay [34]. In all studies the disorder with the worst neurological prognosis, is ASLD. In the Finnish series, all ASLD patients that survived had some type of impairment and 30\% were epileptic, despite the fact that some had been diagnosed before birth, had early treatment, and an absence of hyperammonemic episodes [6]. In the European series, $65 \%$ of the patients with ASLD had psychomotor or intellectual retardation, all those with symptoms at onset, and even three that were diagnosed by NBS [34]. In our series, $80 \%$ of the patients with ASL deficiency had neurological damage, even one that was diagnosed in the presymptomatic state. This is indicative that there are other factors besides hyperammonemia causing neurological damage, e.g., high concentrations of argininosuccinic acid in the CNS, low production of nitric oxide etc. The frequency of neurological damage in patients with OTC deficiency was $44.6 \%$, similar to those referred in other series $[6,34]$.

Regarding type 1 citrullinemia, in the European non classical series with $67 \%$ of patients diagnosed by NBS, $16 \%$ had psychomotor or intellectual retardation [34]. In our series, neurological damage affected $66 \%$ of patients, probably because $63.6 \%$ of our citrullinemia cases were 
of neonatal onset and only $13.6 \%$ were diagnosed by NBS. Since the expanded NBS has been recently established in our country, these figures might change in the future. Mild variants of citrullinemia, which may possibly be without any clinical significance, have been ascertained in the NBS programs. This is why these programs are being carefully evaluated and citrullinemia has been excluded from the screening panel in some European countries [42].

As in other series, ammonia and glutamine levels at onset were also related to neurological outcome; $75 \%$ of the patients without sequelae had ammonia levels $\leq 270 \mu \mathrm{mol} / \mathrm{L}$. Thus, to improve neurological prognosis it is necessary to have early diagnosis and treatment of hyperammonemia.

Treatment of UCDs combines dietary and pharmacological therapy. In our series, $92 \%$ of the cases were under dietary treatment. A protein restricted diet was used in the European non-classical UCDs series with $82 \%$ of the symptomatic patients and $14 \%$ of the asymptomatic cases [34], and in the American series with $63 \%$ of the total, which includes the asymptomatic heterozygous mothers [22]. The studies describing dietary recommendations for these patients are scarce $[11,18,43-45]$. The importance of low-protein diet, sufficient caloric intake and supplements of EAA, minerals, vitamins and long-chain polyunsaturated fatty acids in order to prevent deficiencies is pointed out in all the studies. In the European Guidelines [11], recently published, dietary recommendations are based on a $\mathrm{C}$-D evidence level. The Guidelines suggest following the $\mathrm{FAO} / \mathrm{WHO} / \mathrm{UNU}$ recommendations for protein and energy requirements [32], adapting them according to clinical data. They recommend administering $20-30 \%$ of the protein (50\% in ARG1 deficiency) in the form of EAA in those patients with low protein tolerance in order to maintain growth and metabolic control. During the last few months, two studies have been published regarding dietary treatment in clinical practice in the UK [33] and in other European countries [46] showing that dietary practices vary widely between European IMD centers, particularly with regard to total protein restriction in early infancy, EAAs and approach to nutritional support.

The amount of protein consumed by our patients decreases with age. It is somewhat lower than in the UK [33] but similar to other European countries [46] and according with the WHO recommendations [32], except in the adult group in which is slightly lower (Table 8). In the group of children younger than a year the protein intake is in the high normal range, but we have to say that 3 out of 4 of these patients have citrullinemia diagnosed by NBS, possibly mild forms of the disease. In the rest of the children the intake of protein is in the low normal range of the WHO recommendations. There is no published data on the caloric intake in large series of patients with UCD and therefore we cannot make comparisons with our data, but we can state that our data is in keeping with that obtained through the WHO recommended formulas. In our study $50 \%$ of the patients received EAA supplementation, this accounts approximately for $20-30 \%$ of the total protein intake. In the UK $30 \%$ of the patients received this supplementation and in the rest of Europe 38\% on average, with notable differences according to country (100\% in Sweden, $64-67 \%$ in Germany and Portugal and 24-29\% in France, Denmark and Italy). In the USA they are recommended for all patients, supplying $50 \%$ of total protein intake in infancy, later reducing this percentage to 25\% [45]. The advantage of the EAA would be to decrease the load of ammonia in the urea cycle, since they contain less nitrogen than natural proteins. Besides, given their lower content in tryptophan, tyrosine and phenylalanine, less tryptophan would go to the CNS in situations of hyperammonemia and the production of serotonin would decrease. Lastly, the higher content in branch-chained amino acids would counteract the deficiency of these amino acids found in patients treated with PBA. Therefore, the tendency is to use them in a greater number of patients.

According to the recommendations, arginine and/or citrulline are used to remove ammonia, taking advantage of the urea cycle reactions that are not blocked. In proximal defects, such as in OTC or CPS1 deficiencies, arginine and/or citrulline have been used in 95\% (64/67) of patients, arginine alone in 19 cases, citrulline alone in 33 cases, and both in 12 cases. There are no studies comparing the efficacy of the two. For distal defects (ASSD and ASLD) arginine has been used in 87\% (27/ 31 ) of the cases in significantly higher doses than those used for proximal defects.

The medications used in UCDs are nitrogen scavenging drugs, $\mathrm{PBA}$ and $\mathrm{SB}$, which remove the ammonia through alternative routes. In our series, $68 \%$ of the symptomatic cases received nitrogen scavenging drugs, a percentage similar to the $66 \%$ in the American series [22], and the $72 \%$ in the European series [34]. In our series, as in the American one, PBA was used more frequently (49.5\%) than SB (3.96\%) or the combined therapy (9.9\%). In the American series [22], PBA was used in $58 \%$ of the cases and $\mathrm{SB}$ in $8 \%$ of the symptomatic cases. Conversely, in the European series [34], SB was given to $23 \%$ of the patients, PBA to $13 \%$, and both to $16 \%$. Furthermore, in our series the age of the patients that were given SB was significantly higher than those to which $\mathrm{SB}$ was administered, indicating that the current tendency is to prescribe PBA.

Surprisingly, many patients in our series are still receiving carnitine. Its use was advocated by some in the past, but has proven to be of little benefit in these disorders and not recommended in the last European guidelines. 
In summary, in Spain there are currently 100 living patients registered with UCDs, of which $87 \%$ were indexpatients diagnosed due to symptoms. $25 \%$ have reached adulthood and 52\% have neurological damage. $92 \%$ of the patients are under nutritional therapy, consisting of a normocaloric, low-protein diet, supplemented with EAA in $50 \%$ of the cases. $87 \%$ of the cases with ASS/ ASL deficiency receive treatment with arginine, and 98\% of the patients with OTC/CPS1 deficiency receive arginine and/or citrulline. $68 \%$ of the symptomatic cases are treated with a nitrogen scavenging drug, mainly sodium phenylbutyrate. The Z-score of the weight and height of our patients was normal in all age groups, although lower than the median in height, our study being the first to show the anthropometric data in these patients.

\section{Conclusions}

Expanded registries of rare diseases are indispensable to help understand the natural history of these pathologies and how they may change over time due to better diagnostic and therapeutic tools. It also helps understand the pathophysiology of these diseases, as many genetic or phenotypic data may not be reported individually. In our case, we report 18 novel mutations for various deficiencies.

In order to improve the neurological prognosis of these patients, the expanded newborn screening should be extended to the entire country. As well as this, there is a need for greater diffusion of the knowledge regarding these diseases to general pediatricians, neurologists and neonatologists so we can diagnose them in the presymptomatic state or when ammonia is below the levels that cause irreversible neurological damage.

There is a clear need to incorporate specialists who treat adults with these diseases in metabolic units, for the follow up and treatment of patients once they reach adulthood. Likewise, the integration of dietitians, neuropsychologists and social workers in metabolic units are also required to facilitate the multiple needs these patients present.

\section{Availability of supporting data}

OMIM: http://www.ncbi.nlm.nih.gov/omim/

OMIM is a comprehensive, authoritative compendium of human genes and genetic phenotypes that is freely available and updated daily.

HGMD: http://www.biobase-international.com/product/ hgmd

$\mathrm{HGMD}^{\circ}$ Professional is a unique resource providing comprehensive data on human inherited disease mutations to genetics and genomic research. Its compilation enables quick access to both single mutation queries and advanced search applications.

\section{Abbreviations}

UCDs: Urea cycle disorders; NAGSD: N-acetylglutamate synthase deficiency; CPS1D: Carbamoylphosphate synthetase 1 deficiency; OTCD: Ornithine transcarbamylase deficiency; ASSD: Argininosuccinate synthetase deficiency; ASLD: Argininosuccinate lyase deficiency; ARG1D: Arginase 1 deficiency; $\mathrm{HHH}$ : Hyperornithinemia-hyperammonemia-homocitrullinuria; EAA: Essential amino acid; BZ: Sodium benzoate; PBA: Sodium phenylbutyrate; NBS: Newborn screening; AECOM: Spanish Association of Inborn Errors of Metabolism; IMD: Inherited metabolic diseases; SD: Standard deviation; IQR: Interquartile range; CNS: Central Nervous System.

\section{Competing interests}

The authors declare that they have no competing interests.

\section{Authors' contributions}

EMH: clinical data, conception and design, analysis of the data, drafting and coordination of the manuscript. CPC: molecular genetic data analysis and drafting, critical reading of the manuscript. ABQ: clinical data, conception and design, language assessment, collaboration in drafting, critical reading of the manuscript. LAE: clinical data, conception and design, analysis of the data, critical reading of the manuscript. MTGS: clinical data, conception and design, collaboration in drafting, critical reading of the manuscript. PQF:

clinical data, conception and design, collaboration in drafting, critical reading of the manuscript. MLC: clinical data, conception and design, collaboration in drafting, critical reading of the manuscript. Rest of the authors: clinical data, conception and design, critical reading of the manuscript. All authors read and approved the final manuscript.

\section{Acknowledgements}

We would like to thank Dra. Eva Andrés Esteban, from the Health Research University Institute 12 de Octubre (Madrid) for her support with statistical analysis. Special thanks to the geneticists, Dr. Jose Antonio Arranz (Hospital Vall d'Hebron, Barcelona), Dr. Vicente Rubio (Instituto de Biomedicina, Valencia), Dr. Consuelo Climent (Instituto de Biomedicina, Valencia), Dr. María Antonia Vilaseca (Hospital San Joan de Deu, Barcelona), Dr. Lourdes Ruiz Desviat (Centro de Diagnóstico de Enfermedades Moleculares CEDEM-UAM, Madrid) and Dr. Belén Pérez (Centro de Diagnóstico de Enfermedades Moleculares CEDEM-UAM, Madrid) who have been performing with great expertise over the years molecular studies in patients with urea cycle disorders. Finally, we wish to thank to the patients and their families, without them this study could never have been completed.

\section{Author details}

'Pediatric Rares Diseases Unit, Metabolic and Mitochondrial Diseases, Pediatric Department, Hospital Universitario 12 de Octubre. Research Institute $(i+12)$, Madrid, Spain, Avda de Córdoba s/n, 28041 Madrid, Spain. ${ }^{2}$ H.U. de Cruces, Bilbao, Spain. ${ }^{3} \mathrm{H}$. Sant Joan de Déu, Barcelona, Spain. ${ }^{4} \mathrm{H}$. U. Infantil del Niño Jesús, Madrid, Spain. ${ }^{5}$ C.H.U. de Santiago, Santiago de Compostela, Spain. ${ }^{6}$ H. Materno Infantil Carlos Haya, Málaga, Spain. ${ }^{7}$ H.U. Germans Trias i Pujol, Badalona, Spain. ${ }^{8}$ H.U. Ramón y Cajal, Madrid, Spain. ${ }^{9} \mathrm{H}$. Infantil La Fe, Valencia, Spain. ${ }^{10}$ H.U. La Paz, Madrid, Spain. ${ }^{11}$ H.U. Virgen del Rocío, Sevilla, Spain. ${ }^{12}$ H. Vall d'Hebrón, Barcelona, Spain. ${ }^{13}$ H.U. Miguel Servet, Zaragoza, Spain. ${ }^{14} \mathrm{C} . \mathrm{H}$. de Jaén, Jaén, Spain. ${ }^{15} \mathrm{H}$.U. Ntra. Sra. de la Candelaria, Santa Cruz de Tenerife, Spain. ${ }^{16}$ H.U. Materno Infantil de Las Palmas, Las Palmas de Gran Canaria, Spain. ${ }^{17}$ H.C.U. Virgen de la Arrixaca, Murcia, Spain. ${ }^{18}$ C.H.U. de Albacete, Albacete, Spain. ${ }^{19}$ CEDEM. Facultad de Ciencias, Universidad Autónoma de Madrid, Madrid, Spain.

Received: 25 July 2014 Accepted: 7 November 2014 Published online: 30 November 2014

\section{References}

1. Brusilow SW: Arginine, an indispensable amino acid for patients with inborn errors of urea synthesis. J Clin Invest 1984, 74:2144-2148.

2. Brusilow S, Horwich A: Urea cycle enzymes. In The Metabolic and Molecular Bases of Inherited Diseases. 8th edition. Edited by Scriver C, Beaudet A, Sly W, Valle D. New York: McGraw -Hill; 2001:1909-1963.

3. Applegarth DA, Toone JR, Lowry RB: Incidence of inborn errors of metabolism in British Columbia, 1969-1996. Pediatrics 2000, 105(1):e10. 
4. Dionisi-Vici C, Rizzo C, Burlina AB, Caruso U, Sabetta G, Uziel G, Abeni D: Inborn errors of metabolism in the Italian pediatric population. J Pediatr 2001, 140:321-327.

5. Sanderson S, Green A, Perece M, Burton H: The frequency of inherited metabolic disorders in the west midlands, United Kigdom. Arch Dis Child 2006, 91:896-899.

6. Keskinen P, Siitonen A, Salo M: Hereditary urea cycle diseases in Finland. Acta Paediatr 2008, 97:1412-1419.

7. Summar ML, Stefan Koelker S, Freedenberg D, Le Mons C, Haberle J, Lee HS, Kirmse B, the European Registry and Network for Intoxication Type Metabolic Diseases (E-IMD), the Members of the Urea Cycle Disorders Consortium (UCDC): The incidence of urea cycle disorders. Mol Genet Metab 2013, 110:179-180.

8. Saudubray JM, Nassogne MC, de Lonlay P, Touati G: Clinical approach to inherited metabolic disorders in neonates: an overview. Semin Neonatol 2002, 7:3-15.

9. Summar ML, Dobbelaere D, Brusilow S, Lee B: Diagnosis, symptoms frequency and mortality of 260 patients with urea cycle disorders from a 21-year multicenter study of acute hyperammonaemic episodes. Acta Paediatr 2008, 97:1420-1425.

10. Wijburg FA, Nassogne MC: Disorders of the urea cycle and related enzymes. In Inborn Metabolic Diseases, Diagnosis and Treatment. 5th edition. Edited by Saudubray JM, van den Berghe G, Walter JH. Berlin Heidelberg: Springer- Verlag; 2012:297-309.

11. Häberle J, Boddaert N, Burlina A, Chakrapani A, Dixon M, Huemer M, Karall D, Martinelli D, Crespo PS, Santer R, Servais A, Valayannopoulos V, Lindner M, Rubio V, Dionisi-Vici C: Suggested guidelines for the diagnosis and management of urea cycle disorders. Orphanet J Rare Dis 2012, 7:32.

12. Sander J, Janzen N, Sander S, Steuerwald U, Das AM, Scholl S, Trefz FK Koch HG, Haberle J, Korall H, Marquardt I, Korenke C: Neonatal screening for citrullinaemia. Eur J Pediatr 2003, 162:417-420.

13. Mercimek-Mahmutoglu S, Moeslinger D, Häberle J, Engel K, Herle M, Strobl MW, Scheibenreiter, Muehl A, Stöckler-Ipsiroglu: Long-term outcome of patients with argininosuccinate lyase deficiency diagnosed by newborn screening in Austria. Mol Genet Metab 2010, 100:24-28.

14. Summar M: Current strategies for the management of neonatal urea cycle disorders. J Pediatr 2001, 138:S30-S39.

15. Couce ML, Bustos G, García-Alixc A, Lázaro A, Martínez-Pardo M, Molina A, Saénz de Pipaón M, Serrano M, Sanjurjo P: Guía clínica de diagnóstico y tratamiento urgente de hiperamonemia neonatal. An Pediatr (Barc) 2009, 70:183-188.

16. Schaefer F, Straube E, Oh J, Mehls O, Mayatepek E: Dialysis in neonates with inborn errors of metabolism. Nephrol Dial Transplant 1999, 14:910-918.

17. Picca S, Dionisi-Vici C, Abeni D, Pastore A, Rizzo C, Orzalesi M, Sabetta G, Rizzoni G, Bartuli A: Extracorporeal dialysis in neonatal hyperammonemia: modalities and prognostic indicators. Pediatr Nephrol 2001, 16:862-867.

18. Scaglia F: New insights in nutritional management and amino acid supplementation in urea cycle disorders. Mol Genet Metab 2010, 100(Suppl 1):S72-S76.

19. Enns GM, Berry SA, Berry GT, Rhead WJ, Brusilow SW, Hamosh A: Survival after treatment with phenylacetate and benzoate for urea-cycle disorders. N Engl J Med 2007, 356:2282-2292.

20. Stevenson T, Millan MT, Wayman K, Berquist WE, Sarwal M, Johnston EE, Esquivel CO, Enns GM: Long-term outcome following pediatric liver transplantation for metabolic disorders. Pediatr Transplant 2009, 14:268-275.

21. Kim IK, Niemi AK, Krueger C, Bonham CA, Concepcion W, Cowan TM, Enns GM, Esquivel CO: Liver transplantation for urea cycle disorders in pediatric patients: a single-center experience. Pediatr Transplant 2013, 17:158-167.

22. Tuchman M, Lee B, Lichter-Konecki U, Summar ML, Yudkoff M, Cederbaum SD, Kerr DS, Diaz GA, Seashore MR, Lee HS, McCarter RJ, Krischer JP, Batshaw ML, Urea Cycle Disorders Consortium of the Rare Diseases Clinical Research Network: Cross-sectional multicenter study of patients with urea cycle disorders in the United States. Mol Genet Metab 2008, 94:397-402.

23. Kölker S, Dobbelaere D, Chaprani A, Parker S, Burgard P, Hoffmann G, De Baere L, Stroobant N, Haeberle J, Baumgartner M: European registry and network for intoxication type metabolic diseases (E-IMD)(Abstract). J Inher Matabolic Dis 2011, 34:s93.

24. García-Pérez MA, Sanjurjo P, Rubio V: Demonstration of the spf-ash mutation in Spanish patients with ornithine transcarbamylase deficiency of moderate severity. Hum Genet 1995, 95:183-186.
25. Climent C, García-Pérez MA, Sanjurjo P, Ruiz-Sanz Jl, Vilaseca MA, Pineda M, Campistol J, Rubio V: Identification of a cytogenetic deletion and of four novel mutations (Q69X, I172F, G188V, G197R) affecting the gene for ornithine transcarbamylase (OTC) in Spanish patients with OTC deficiency. Hum Mutat 1999, 4:352-353.

26. Climent $C$, Rubio $V$ : Identification of seven novel missense mutations, two splice-site mutations, two microdeletions and a polymorphic amino acid substitution in the gene for ornithine transcarbamylase (OTC) in patients with OTC deficiency. Hum Mutat 2002, 19:185-186.

27. Arranz JA, Riudor E, Marco-Marín C, Rubio V: Estimation of the total number of disease-causing mutations in ornithine transcarbamylase (OTC) deficiency. Value of the OTC structure in predicting a mutation pathogenic potential. J Inherit Metab Dis 2007, 30:217-226.

28. Vilaseca MA, Kobayashi K, Briones P, Lambruschini N, Campistol J, Tabata A Alomar A, Rodès M, Lluch M, Saheki T: Phenotype and genotype heterogeneity in Mediterranean citrullinemia. Mol Genet Metab 2001, 74:396-398.

29. Hernández M, Castellet J, Narvaiza JL, Rincón JM, Ruiz I, Sánchez E, Sobradillo B, Zurimendi A: Curvas y tablas de crecimiento. In Instituto de Investigación sobre Crecimiento y Desarrollo. Fundación F. Orbegozo. Bilbao. 3a Edición. Madrid: Ediciones Ergón; 2002.

30. Bélanger-Quintana A, Martínez-Pardo M, García MJ, Wermuth B, Torres J, Pallarés $E$, Ugarte M: Hyperammonaemia as a cause of psicosis in an adolescent. Eur J Pediatr 2003, 162:773-775.

31. Stenson PD, Mort M, Ball EV, Shaw K, Phillips AD, Cooper DN: HMGD professional The Human Gene Mutation Database: building a comprehensive mutation repository for clinical and molecular genetics, diagnostic testing and personalized genomic medicine. Hum Genet 2014, 133:1-9.

32. Who/FAO/UNU Expert consultation: Protein and Amino Acid Requirements in Human Nutrition, WHO Technical Reports Series 935. Geneva: UNU/WHO; 2007

33. Adam S, Champion H, Daly A, Dawson S, Dixon M, Dunlop C, Eardley J, Evans S, Ferguson C, Jankowski C, Lowry S, MacDonald A, Maritz C, Micciche A, Robertson L, Stafford J, Terry A, Thom R, van Wyk K, Webster D, White FJ, Wildgoose J, British Inherited Metabolic Diseases Group (BIMDG) Dietitian's Group: Dietary management of urea cycle disorders: UK practice. J Hum Nutr Diet 2012, 25:398-404

34. Rüegger $C M$, Lindner $M$, Ballhausen $D$, Baumgartner MR, Beblo S, Das A, Gautschi M, Glahn EM, Grünert SC, Hennermann J, Hochuli M, Huemer M, Karall D, Kölker S, Lachmann RH, Lotz-Havla A, Möslinger D, Nuoffer JM, Plecko B, Rutsch F, Santer R, Spiekerkoetter U, Staufner C, Stricker T, Wijburg FA, Williams M, Burgard P, Häberle J: Cross-sectional observational study of 208 patients with non-classical urea cycle disorders. J Inherit Metab Dis 2014, 37:21-30.

35. Instituto Nacional de Estadística. http://www.ine.es/

36. Tuchman M, Morizono H, Rajagopal BS, Plante RJ, Allewell NM: The biochemical and molecular spectrum of ornitine transcarbamylase deficiency. J Inherit Metab Dis 1998, 21(Suppl 1):40-58.

37. Tuchman M, Jaleel N, Morizono H, Sheeby L, Lynch MG: Mutations and polymorphisms in the human ornithine transcarbamylase (OTC) gene. Hum Mutat 2002, 19:93-107.

38. Mavinakere M, Morizono $H$, Shi D, Alewell NM, Tuchman M: The clinically variable $\mathrm{R} 4 \mathrm{OH}$ mutant ornithine carbamoyltransferase shows cytosolic degradation of the precursor protein in $\mathrm{CHO}$ cells. J Inherit Metab Dis 2001, 24:614-622.

39. Haberle J, Pauli S, Linnebank M, Kleijer WJ, Bakker HD, Wanders RJA, Harms E, Koch HG: Structure of the human argininosuccinate synthetase gene and an improved system for molecular diagnostics in patients with classical and mild citrullinemia. Hum Genet 2002, 110:327-333.

40. Kleijer WJ, Garritsen VH, Linnebank M, Mooyer P, Huijmans JG, Mustonen A, Simola KO, Arslan-Kirchner M, Battini R, Briones P, Cardo E, Mandel H, Tschiedel E, Wanders RJ, Koch HG: Clinical, enzymatic and molecular genetic characterization of a biochemical variant type of argininosuccinic aciduria: prenatal and postnatal diagnosis in 5 unrelated families. J Inherit Metab Dis 2002, 25:399-410.

41. Ficicioglu C, Mandell R, Shih VE: Arginosuccinate lyase deficiency: longterm outcome of 13 patients detected by newborn screening. Mol Genet Metab 2009, 98:273-277.

42. Lindner M, Gramer G, Haege G, Fang-Hoffmann J, Schwab KO2, Tacke U, Trefz FK, Mengel E, Wendel U, Leichsenring M, Burgard P, Hoffmann JF: 
Efficacy and outcome of expanded newborn screening for metabolic diseases - Report of 10 years from South-West Germany. Orphanet J Rare Dis 2011, 6:44-53.

43. Urea cycle Disorders Conference Group: Consensus statement from a conference for the management of patients with urea cycle disorders. J Pediatr 2001, 138:s1-s5.

44. Acosta PB, Yanicelli S, Ryan AS, Arnold G, Marriage BJ, Plewinska M, Bernstein L, Fox J, Lewis V, Miller M, Velazquez A: Nutritional therapy improves growth and protein status of children with urea cycle enzyme defect. Mol Genet Metab 2005, 86:448-455.

45. Singh RH: Nutritional management of patients with urea cycle disorders. J Inherit Metab Dis 2007, 30:880-887.

46. Adam S, Almeida MF, Assoun M, Baruteau J, Bernabei SM, Bigot S,

Champion H, Daly A, Dassy M, Dawson S, Dixon M, Dokoupil K, Dubois S, Dunlop C, Evans S, Eyskens F, Faria A, Favre E, Ferguson C, Goncalves C, Gribben J, Heddrich-Ellerbrok M, Jankowski C, Janssen-Regelink R, Jouault C, Laguerre C, Le Verge S, Link R, Lowry S, Luyten K, et al: Dietary management of urea cycle disorders: European practice. Mol Genet Metab 2013, 110:439-445.

doi:10.1186/s13023-014-0187-4

Cite this article as: Martín-Hernández et al:: Urea cycle disorders in Spain: an observational, cross-sectional and multicentric study of 104 cases.

Orphanet Journal of Rare Diseases 2014 9:187.

\section{Submit your next manuscript to BioMed Central and take full advantage of:}

- Convenient online submission

- Thorough peer review

- No space constraints or color figure charges

- Immediate publication on acceptance

- Inclusion in PubMed, CAS, Scopus and Google Scholar

- Research which is freely available for redistribution 